\title{
A Mechanical Model for an Artificial Oocyte
}

\author{
Amir M. Hajiyavand, Mozafar Saadat, and Artemis Stamboulis
}

\begin{abstract}
Cell injection to introduce a foreign material in biological cells is currently an important area of research. Intervention with biological cells such as an oocyte poses a major limitation towards understanding their biomechanical behaviour, especially during injection, which could result in significant and undesirable deformation of the outer membrane. In this paper, a cross-linked alginate hydrogel is proposed as a material to develop an artificial oocyte to simulate the mechanical properties of a natural human oocyte and use it for mechanical analysis and modelling. A mechanical model and finite element analysis are first presented. The relationship between the injection force and the mechanical properties of the gel are then studied and presented. To validate the mechanical model, experiments were performed using different diameters of an oocyte made using the proposed hydrogel, showing that the modelling results satisfy the experimental demands and that this model can be used to estimate the mechanical properties of other gels too.
\end{abstract}

Index Terms-Artificial oocyte, alginate, hydrogel, finite element model, deformation.

\section{INTRODUCTION}

Many researchers have focused on micro-injection technology which has been proved to be an effective technique introducing foreign materials into cells. This technology can be applied for gene injection, In-vitro fertilisation (IVF), intra-cytoplasmic sperm injection (ICSI), drug development and other biomedical areas notably in cancer treatments [1]. To the best knowledge of the authors, this is the first report of proposing a material for fabricating an artificial oocyte.

Accessing human biological oocyte samples for experimental work is very limited, and therefore having suitable artificial samples that could mimic the natural tissues would help to develop appropriate experimental methodology.

Synthetic and natural polymers could be considered for the development of artificial tissues. In 2017 alginate hydrogels were proposed for transplantation of ovarian follicles considering different grafting times [2]. Alginate is one of the proposed materials which has the minimum grafting time that is reported to be one week [3]. Alginate

Manuscript received October 20, 2017, revised November 30, 2017. The paper title is A Mechanical Model for an Artificial Oocyte.

A. M. Hajiyavand and M. Saadat are with the Department of Mechanical Engineering, School of Engineering, University of Birmingham, Edgbaston, Birmingham, B15 2TT, United Kingdom (e-mail: axh047@bham.ac.uk,m.saadat@bham.ac.uk).

A. Stamboulis is with the School of Metallurgy and Materials, University of Birmingham, Edgbaston, Birmingham, B15 2TT, United Kingdom (e-mail: a.stamboulis@bham.ac.uk). has found wide applications as a scaffold for drug delivery. It is biocompatible and shows non antigenicity [4]. Alginate was also proposed as a candidate material for transplantable artificial ovary matrices in 2012 [3], [5]. It has also been reported that different combinations with alginate such as matrigel could be successfully employed for transplanting murine ovarian cells [3]. In 2007, a link was reported for the first time which showed the direct connection between follicle function and biomechanical environment. This showed the influence of alginate hydrogel on the follicle growth [6]. Alginate hydrogel and its solidifications levels have been reported for ovarian follicle development and tissue forming [6]-[8].

To achieve desirable mechanical properties, crosslinking should be appropriately controlled. The alginate hydrogel's mechanical properties can be significantly affected by the type and density of crosslinks [9], [10].

Although, the area of micro injection has been developed considerably during the last ten years, little attention has been paid to the mechanical modelling and characteristics of biological cells. Obtaining the mechanical properties and characteristics of an oocyte as a biological cell can provide the knowledge for improving intracytoplasmic sperm injection conditions. On the other hand, this research can be the platform for further developing artificial oocytes in order to overcome oocyte deficiencies which are one of the major causes of cell death.

This paper mainly focuses on developing an artificial oocyte made of alginate hydrogel with controlled crosslinking in order to obtain mechanical properties that are very close to the human oocyte. The obtained results are compared to the human oocyte mechanical properties from previous work reported in the literature.

\section{MOdEL PRESENTATION}

Mechanical properties of biological samples are essential considerations in the area of developing custom-made biological scaffolds for specific tissue regeneration and repair. In this paper a mechanical model is proposed which can help the understanding of the behavior of the developed artificial oocyte samples in relation to the induced force during injection, as demonstrated in a preliminary study [11].

An oocyte cell is made of different layers; the most outer layer which covers the whole sub-structures is called zona pellucid. Another layer present within the oocyte is called Oolemma. These two layers play the most important role in the deformation that occurs on the oocyte membrane during injection. In addition, the sub-structures of these two layers play important roles in defining the mechanical properties of the oocyte before and during the injection. 
In this section, a mechanical model is initially developed that can take into consideration the properties of the material used in order to predict the artificial oocyte behavior.

The following assumptions were made in order to develop the artificial oocyte:

1) The oocyte is spherical and its material is crosslinked.

2) The total volume of the cell does not change during injection.

3) The layers have a negligible flexural rigidity, so that the deformation is only caused due to layer stretching. The cross-linked material is free from initial and residual stresses.

4) The dynamical factors of the injection process are constant.

5) The material (gel) is isotropic, incompressible and homogeneous.

Fig. 1 demonstrates the injection force and deformation creation during the injection. In this figure, the injector force is illustrated by $\mathrm{F}$.

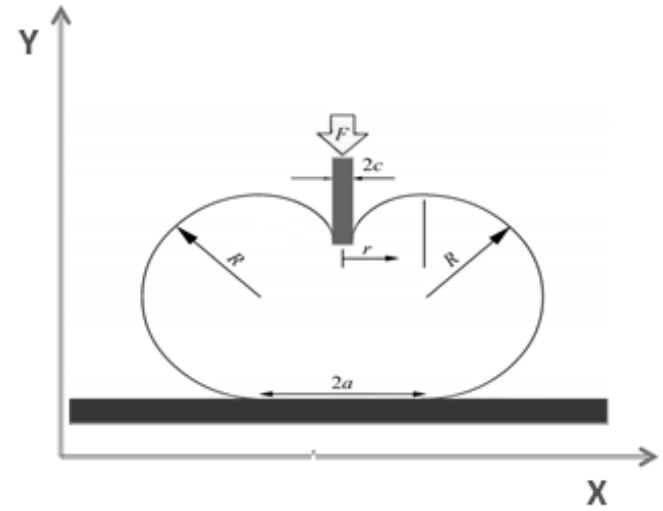

Fig. 1. Schematic view of injection procedure.

In the mechanical modelling of the cell injection, the force analysis is essential. The point-load model [12] (Equation 1) was used:

$$
\sum \mathrm{F}_{\mathrm{y}}=\mathrm{ma}=\mathrm{m} \frac{\mathrm{dV}}{\mathrm{dx}}
$$

where $m$ is the mass of the injector (needle) in $\mathrm{Kg}$ and $a$ is the acceleration of the injector in $\mathrm{m} / \mathrm{s}^{2}$.

As it was mentioned before, the speed as a dynamical factor was assumed to be constant and therefore the force balance should be zero (no acceleration occurs at the time of injection) [12]:

$$
\sum \mathrm{F}_{\mathrm{y}}=0 \text { so } \mathrm{F}-\mathrm{F}_{\mathrm{p}}-2 \sigma_{\mathrm{d}} \pi \mathrm{rh} \frac{\mathrm{dw}}{\mathrm{dx}}=0
$$

where $F$ is the injection force in $\mathrm{N}, \mathrm{F}_{\mathrm{p}}$ is the internal pressure acting on the outer surface of the artificial oocyte and $\sigma_{d}$ is the stress at the injection section. Also $\frac{d w}{d x}$ is the dimple profile changing due to the changing in radius. In terms of finding the forces, the Mooney-Rivlin model must be adapted thus, by employing the strain energy function as the inside pressure is un-known.
The tension of hydrogel surface for the experimental samples has been obtained from the strain energy function (Equation 3) considering the oocyte as a single layered cell [13], [14].

$$
W=C_{1}\left(I_{1}-3\right)+C_{2}\left(I_{2}-3\right)
$$

where $\mathrm{C}_{1}$ and $\mathrm{C}_{2}$ are the material constants which control the shear behavior of the sample and can be achieved from uniaxial tests, $I_{1}$ and $I_{2}$ are the strain invariant which are related to the material. If $\alpha=\mathrm{C}_{2} / \mathrm{C}_{1}$, then the strain energy equation can be written as:

$$
W=C_{1}\left[\left(I_{1}-3\right)+\alpha\left(I_{2}-3\right)\right]
$$

$\mathrm{C}_{1}$ and $\mathrm{C}_{2}$ can be obtained through experiments. $\mathrm{C} 1$ is determined through uniaxial compression mechanical tests while $\mathrm{C}_{2}$ must be obtained through biaxial tests while $\mathrm{I}_{1}$ and $\mathrm{I}_{2}$ can be obtained as following:

$$
\begin{aligned}
& I_{1}=\lambda_{1}{ }^{2}+\lambda_{2}{ }^{2}+\lambda_{3}{ }^{2} \\
& I_{2}=\frac{1}{\lambda_{1}{ }^{2}}+\frac{1}{\lambda_{2}{ }^{2}}+\frac{1}{\lambda_{3}{ }^{2}}
\end{aligned}
$$

where $\lambda$ is the ratio of the new dimension over the original in each directions as shown in Figure 2 and Equation 6. It is assumed that the alginate gel is homogeneous, isotropic and incompressible material. Consequently, $\mathrm{C}_{\mathrm{i}}$ can be equal to $\frac{E}{6(1+\alpha)}$. If the area exerted by the external injection force was considered as an element, then $\lambda$ would be obtained from Equation 6, as shown in Figure 2. This demonstrates the exerted injection force on the particular element and explained the dimension changes in each direction.

$$
\lambda_{1}=\frac{d x_{1}}{d x_{2}}, \lambda_{2}=\frac{d y_{1}}{d y_{2}}, \lambda_{3}=\frac{1}{\lambda_{1} \lambda_{2}}
$$

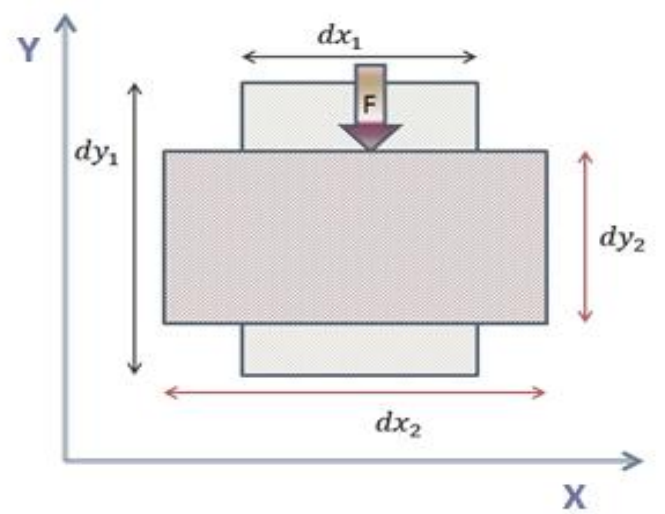

Fig. 2. The schematic view of the oocyte element during injection

The surface tension can be calculated by the following equations [1]:

$$
T_{i}=\frac{h}{\lambda_{1} \lambda_{2}} \lambda_{i} \frac{\partial W}{\partial \lambda_{i}},(i=1,2)
$$


where $h$ is the thickness of the layer in meter.

The external pressure can be obtained by:

$$
P=K_{1} T_{1}+K_{2} T_{2}
$$

where $K$ describes the principal curvature and can be achieved by [1]:

$$
K_{i}^{2}=I_{i}-3
$$

where $I_{i}$ is obtained from equation 5 .

As a result, the final equation which indicates the role of the material properties in expressing the mechanical factors is obtained as following:

$$
\begin{aligned}
& {\left[\frac{2 h K_{1}}{\lambda_{1} \lambda_{2}}\left(\lambda_{1}{ }^{2}-\frac{1}{\lambda_{1}{ }^{2} \lambda_{2}{ }^{2}}\right)\left(C_{1}+\lambda_{2}{ }^{2} C_{2}\right)+\frac{2 h K_{2}}{\lambda_{1} \lambda_{2}}\left(\lambda_{2}{ }^{2}-\right.\right.} \\
& 1 \lambda 12 \lambda 22 C 1+\lambda 12 C 2 . \pi a 2-F p-2 \sigma d \pi r h d w d x=0
\end{aligned}
$$

\section{AlginAtes For ARTificial OOCYTE DEVElopMent}

Searching for appropriate biomaterial which has similar mechanical properties to the ovarian samples is crucial. A number of variant polymers, classified as natural and synthetic polymers, have been reported for the construction of artificial ovaries [2]. Here, alginate acid sodium salt, as a type of hydrogel, was selected for the modeling of the proposed artificial oocyte due to its versatility, and also the fact that it has been reported as a suitable material for transplantable artificial ovary matrix [15], [16].

Alginate hydrogel because of their inherent properties and the interaction of alginates with proteins, fibres and fats has varied applicability as a biomaterial, such as drug delivery, scaffolding for tissue engineering, as an implant, etc. Using this hydrogel requires control of the material properties, including mechanical stiffness, swelling, degradation, cell attachment and binding or release of bioactive molecules. The benefits of these developed alginate gels as biomaterials have been shown in many in vitro and in vivo studies [18].

"Alginates are polysaccharides isolated from brown algae such as Laminaria hyperborean and lessonia found in coastal waters around the globe" [19].

Alginate hydrogels, due to their unique biocompatibility and desirable physical characteristics, are chosen materials in many applications in medicine.

Cross-linking of the gel and control of the degree of crosslinking are important factors for the use of alginates. Crosslinking occurs with the addition of calcium chloride solution. This reaction could be either bulk or surface depending on how calcium chloride is used. ${ }^{\prime C} \mathrm{CaCl}_{2}$ as a gelling agent has been used to achieve a more rapid cross linking of the alginate gels and gel beads for cellular encapsulation." [20]. Calcium chloride has the power to link one polymer chain to another. These polymer chains can be synthetic polymers or natural polymers such as proteins. It is used to link proteins together to check the interaction of the chains [18]. But understanding the suitable dose of the alginate acid salt (indicated in percentages) and the molarities of the calcium chloride used in this study for crosslinking the gel are main issues. Three different concentrations of alginate salt, 2, 5 and $10 \mathrm{wt} / \mathrm{v} \%$ in $100 \mathrm{ml}$ water were dissolved. Three different concentrations of $\mathrm{CaCl}_{2} 0.1,0.5$, and $1 \mathrm{M}$ were also considered in order to study the dependence of the degree of crosslinking on the amount of crosslinking agent used. The crosslinking reaction (here it will be called as solidification) was mainly divided into two main parts as outer layer solidification and inner layer solidification. It was expected that the outer layer would be stronger and would cover and protect the cell, while the inner part would be jelly and softer. In order to make the artificial oocytes round, an in-house mould was designed and built using a 3D printer This mould has sphere cavities of four different sizes $(15,10,5$ and $2 \mathrm{~mm})$. The material used for the mould was Fulcure 720 which is a photopolymer resins. The mould was designed so that different oocyte sizes (different diameter) could be prepared. A duct was included for each cell so that that the alginate gel could be injected in the mould.

Before the gel injection, the surrounding of each mould was covered by filter papers which were merged in $\mathrm{CaCl}_{2}$ and wetted properly. Then, the gel was injected through the predesigned duct to the mould. After solidifying the surface of the gels, a small amount of calcium chloride was injected into the gel in the mould in order to make the inner gel, more viscous.

Controlling the amount of solidification surrounding the cell was another challenge. Quantified experimental data are

\begin{tabular}{|c|c|c|c|}
\hline $\begin{array}{l}\text { Calcium Chloride } \\
\text { (concentration) }\end{array}$ & $\begin{array}{c}10 \% \text { Alginate salt } \\
\text { gel }\end{array}$ & $\begin{array}{c}5 \% \\
\text { Alginate } \\
\text { salt gel }\end{array}$ & $\begin{array}{c}2 \% \\
\text { Alginate } \\
\text { salt gel }\end{array}$ \\
\hline $0.1 \mathrm{M}$ & $\begin{array}{l}10 \% \text { soft } \mathrm{CL}^{*} \text { and } \\
\text { liquid inside }\end{array}$ & $\begin{array}{c}25 \% \text { soft } \\
\text { CL and } \\
\text { liquid } \\
\text { inside }\end{array}$ & No CL \\
\hline $0.5 \mathrm{M}$ & $\begin{array}{l}50 \% \text { hard CL and } \\
\text { liquid inside }\end{array}$ & $\begin{array}{l}85 \% \text { soft } \\
\text { CL and } \\
\text { viscous } \\
\text { inside }\end{array}$ & $\begin{array}{c}100 \% \text { soft } \\
\text { CL and } \\
\text { viscous } \\
\text { liquid } \\
\text { inside }\end{array}$ \\
\hline $1.0 \mathrm{M}$ & $\begin{array}{l}10 \% \text { CL and } \\
\text { liquid inside }\end{array}$ & $\begin{array}{c}10 \% \mathrm{CL} \\
\text { and liquid } \\
\text { inside }\end{array}$ & $\begin{array}{c}\text { Not } \\
\text { possible }\end{array}$ \\
\hline
\end{tabular}
shown in Table I.

TABLE I: EXPERIMENTAL PRESENTATION FOR THE RECOGNITION OF SUITABLE DOSES FOR GEL AND CROSS LINKER

- $\quad \mathrm{CL}=$ Cross linking

The table indicates that $2 \%$ alginate with $0.5 \mathrm{M}$ calcium chloride was suitable for this study. This result was obtained after almost 20 experiments.

The first set of experiments were conducted to identify what amount of alginate sodium salt powder and how much calcium chloride would be best for making the artificial oocyte. The second set of experiments were used to ascertain the amount of calcium chloride which should be injected in the mould for a particular oocyte. In terms of cross linking, the alginate hydrogel, different concentrations of calcium chloride were added to the gel.

The proposed material is biocompatible and has the most 
similarities to the natural human oocyte which is consisted of proteins. The zona pellucida, the outermost layer of the oocyte, consists of three different glycoproteins. They are interchangeably connected to each other and make fibril structures which are cross linked [21].

Controlling the cross linking of the gel helped to model the artificial oocyte as close as possible to the real cell. The mechanical properties of gel, such as stiffness can be controlled by physical factors, such as cross-linking density, cross-link type and molecular weight distribution, and also by chemically modifying the polymer [22]. These can affect the mechanical behaviour of the gel [20].

\section{FINITE ELEMENT MODELLING OF ARTIFICIAL OOCYTE}

Abacus finite element software tool was employed to simulate the compression test experiments and compare the results with the experimental ones. It was employed for precise prediction of the sample behaviour when it is subjected to either a distributed force (exerted by a plate), or a concentrated force exerted by a needle. There are two different model types defined for hyperelastic materials such as phenomenological model and physically motivated model [14]. In this model, the strain-stress is characterized without considering the microscopic structure and analysis considerations using continuum model, which is referred to as the phenomenological model. The FE model was defined by quadric hex elements with integration reduction (C3D20RH) as the selected mesh type which is suitable for hyperelastic materials, and quadric element form due to its higher accuracy in comparison to linear element. The loading model was tested under the same loading conditions as the experiments. In this model, the gel is placed between two plates, the bottom one being fixed and the upper one moving (hence simulating a compression test). Compression forces in the range $\mathbf{0 - 1 0 N}$ were applied to the gel, as shown in Fig. 3.

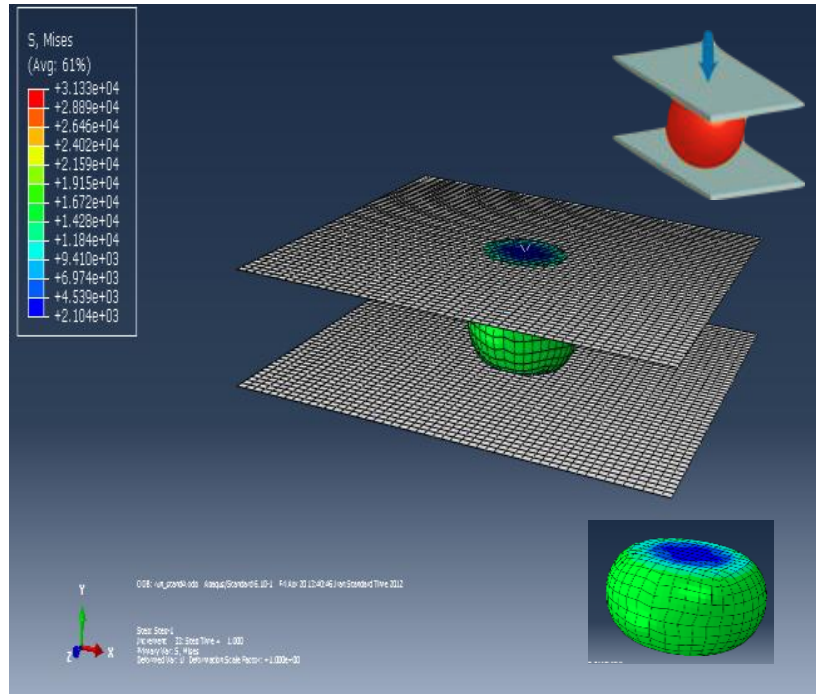

Fig. 3. FEM simulation of compression test for the sample enclosed between two plates.

The cell was modeled as a spherical shape in Abaqus using Alginate hydrogel as the defined material. The behaviour of the hyperelastic material is defined by the Mooney-Rivlin hyperelastic model. The values of material constants $\mathrm{C} 1$ and $\mathrm{C} 2$ given in Equation 3 were evaluated by the given stress strain data obtained from the experimental tests and were defined into the Abaqus software.

This modelling help the understanding of the reaction behaviour of the samples when they were subjected to an applied force under compression or during injection. The mechanical properties of various samples using a particular solidified gel after a single experiment could be determined. The retrieved data was specified as stress-strain pairs to calculate $\mathrm{C}_{\mathrm{i}}$ and the compressibility constant.

\section{RESULTS AND DISCUSSIONS}

The results have been divided into three main sections. Initially, the samples were subjected to compression mechanical tests. The second part s focuses on analyzing the artificial cell behaviour when the cells are subjected to the injection process. The mechanical test data also feed a Finite Element (FE) model to satisfy the proposed model. The final section discusses the proposed FE model and compares the results with the experimental data.

This section indicates the mechanical results of the alginate gel when tested by the compression test device (Zwick/Roell Z030). This device tested the compressive strength as a mechanical property of the gel. This test was done to understand the properties, to improve the material selection and compare them to the modelling results for an artificial oocyte. The comparison test has been applied to find out the material constant needed for Mooney-Rivlin Model. The compression speed was $0.1 \mathrm{~mm} / \mathrm{s}$ for all the samples with the dimensions of $15,10,5$ and $2 \mathrm{~mm}$.

As it is indicated in Figure 4, the cell was subjected to the uniform speed of compression using $10 \mathrm{~mm}$ plate till the point of gel puncture and the reported loads were recorded.

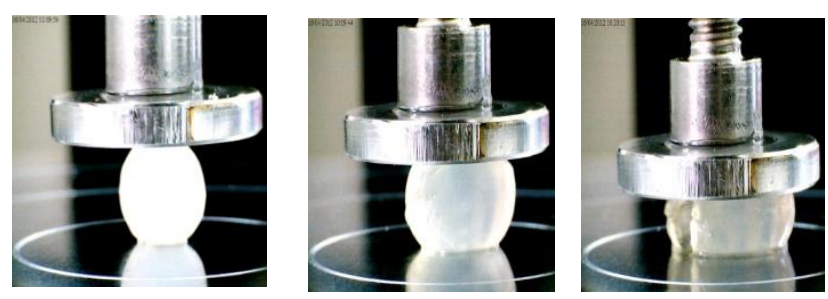

Fig. 4. Compression experiment for the samples.

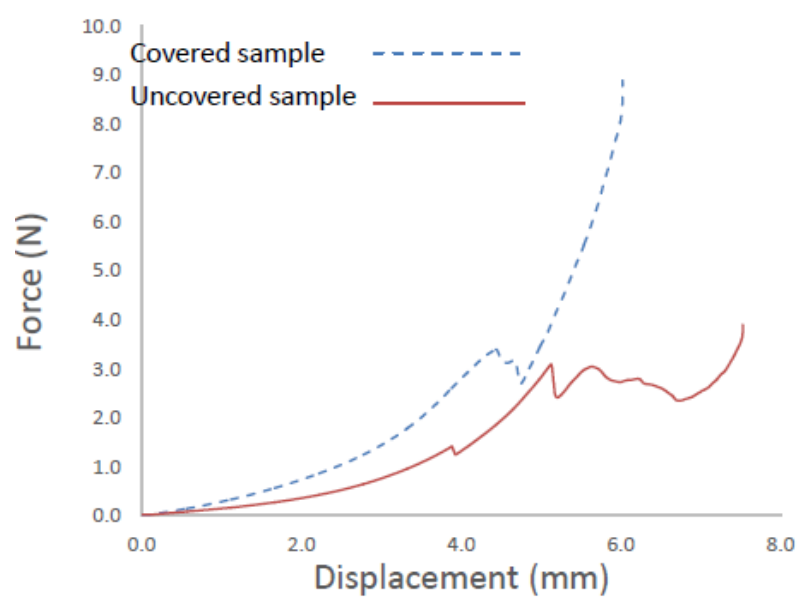

Fig. 5. Comparison between the samples with diameters of $10 \mathrm{~mm}$, one covered by $1 \mathrm{M} \mathrm{CaCl} 2$ and the other with no cover. 
The main aim of this part of the work is to understand the effect of the sample size on the compression force as well as the effect of the additional crosslinker on the reported compression strength. The recorded force comparison between covered and uncovered samples (10 $\mathrm{mm}$ samples as an example) has been demonstrated in Fig. 5.

The first peaks in the graphs are associated with the formation of cracks in the gel during the compression test. As it can be illustrated from the graphs the degree of crosslinking affects the integrity of the artificial oocytes. Lower degree of crosslinking will lead to puncture and disintegration of the gel network which higher forces needed to puncture in less displacement. Covering the cell indicates the additional process on the outer layer of the samples after removal from the mould. In this process, samples are covered additionally with a filter paper that is previously wetted by $\mathrm{CaCl}_{2}$.

The second section of the results focused on the modeling of the injection process and record the reaction forces to analyse the behavioural response of the artificial cells to the injectors as shown in Figure 6. For this purpose, an in-house setup was designed to model the injection. The force of injection was recorded by an SS2 sensor which was assembled on the tip of an actuator between sensor and injection needle.
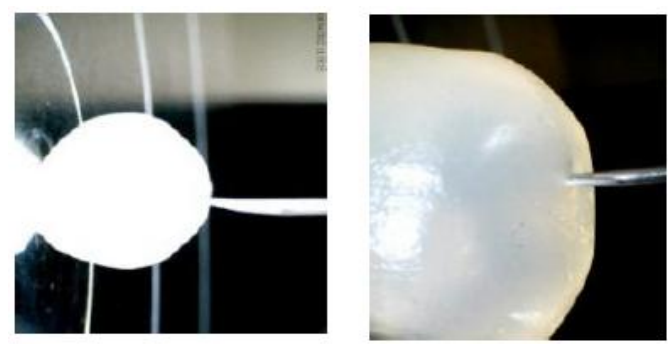

Fig. 6. Sample injection by needle.

The injection profile of the samples was divided in three main categories. Figure 7 illustrates the recorded injection force versus the deformation of the samples of the three categories when they were subjected to needle insertion. All three categories reported similar behaviour of the sample with different reported puncturing loads. The first category is the crosslinking within the mould and without extra crosslinkers after removal from the mould. The second category is with extra $0.5 \mathrm{M} \mathrm{CaCl}_{2}$ and third category is $1 \mathrm{M}$ $\mathrm{CaCl}_{2}$. As the graph illustrates, there is no difference between adding extra cover surrounding the cell after removal and not adding it for $0.5 \mathrm{M} \mathrm{CaCl}_{2}$. Although the cell is more brittle after covering $1 \mathrm{M}$ cover.

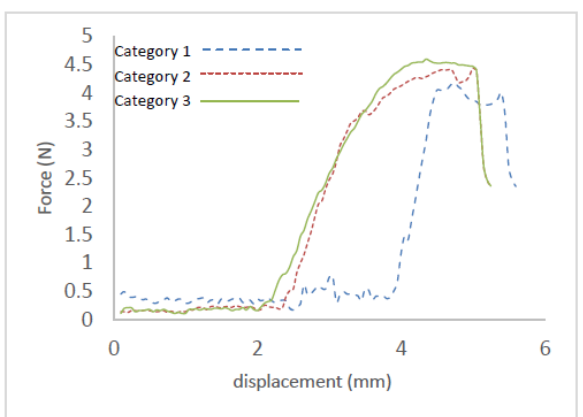

Fig. 7. Three categories of sample injections.
The last section of the results is focused on the proposed FE model using Abacus which helps to develop the experiments on the samples easier without the practice on real cells. The software model was justified by the experiments as shown in Table II. In this table, the obtained results from experiments and FE model are compared in three regions of before puncturing, puncturing and post puncturing.

TABLE II: THE COMPARISON BETWEEN THE DEVELOPED SOFTWARE AND EXPERIMENT FOR VALIDATION

\begin{tabular}{|c|c|c|c|c|}
\hline & DATA & $\begin{array}{c}\text { before } \\
\text { puncturing }\end{array}$ & $\begin{array}{c}\text { puncturing } \\
\text { point }\end{array}$ & $\begin{array}{c}\text { after } \\
\text { puncturing } \\
\text { point }\end{array}$ \\
\hline \multirow[t]{2}{*}{ FE Model } & $\begin{array}{l}\text { displacement } \\
(\mathrm{mm})\end{array}$ & 4.2 & N/A & 8.4 \\
\hline & force $(\mathrm{N})$ & 2 & N/A & 6 \\
\hline \multirow{2}{*}{$\begin{array}{l}\text { Experimental } \\
\text { result }\end{array}$} & $\begin{array}{l}\text { displacement } \\
(\mathrm{mm})\end{array}$ & 4.64 & 5.19 & 8.09 \\
\hline & force $(\mathrm{N})$ & 2 & 2.75 & 6 \\
\hline
\end{tabular}

The minor differences between the model and the experimental data are mainly relying on the experimental errors. As a result, the model is reliable for simulating the samples for different sizes. The Mooney-Rivlin material constants for alginate gel obtained from the modelling test are:

$$
C 1=0.027779 \mathrm{MPa} \quad \mathrm{C2}=-0.011017 \mathrm{MPa}
$$

These constants are material-dependent and will be used to determine the injection force.

Fig. 8a illustrates the force-displacement results obtained from Abaqus model for the $10 \mathrm{~mm}$ diameter sample. Figure $8 \mathrm{~b}$ shows the force-displacement variations obtained in the alginate-made samples experiment. Two randomly selected points, one before and one after the punture point, have been examined in order to validate the results. The first point, A, selected before puncture point, illustrates deformations of $0.004 \mathrm{~m}$ and $0.0045 \mathrm{~m}$ in the FE and experimental results respectively when the samples were subjected to a compression load of $2 \mathrm{~N}$. The second point, B, selected after puncture point, shows $0.0082 \mathrm{~m}$ and $0.008 \mathrm{~m}$ deformation for FE and Experimental results respectively. This demonstrates that the experimental results validated the FE simulation. However, the puncture point was not achieved in the FE simulation. The FE model will assist us to predict the sample behaviour under the subjected force without essentiality of operating tests.

The results of the samples of artificial oocyte with the 0.5 $\mathrm{M} \mathrm{CaCl} 2$ is compared with the reported graph for the real oocyte, as shown in Figure 9. The graph of the injection mainly describes three different regions. The first region shows no needle contact with the artificial cell, the second region illustrates the time of injection which includes the resulting deformation, and the third region shows puncture has occurred.

In the second region, the recorded force was initially increased sharply, and then slowly, until puncture occurs. This was the same phenomenon for the real embryo reported in Fig. 9b [1]. The results indicate a similar response behaviour of the proposed hydrogel when it was subjected to the injector. 

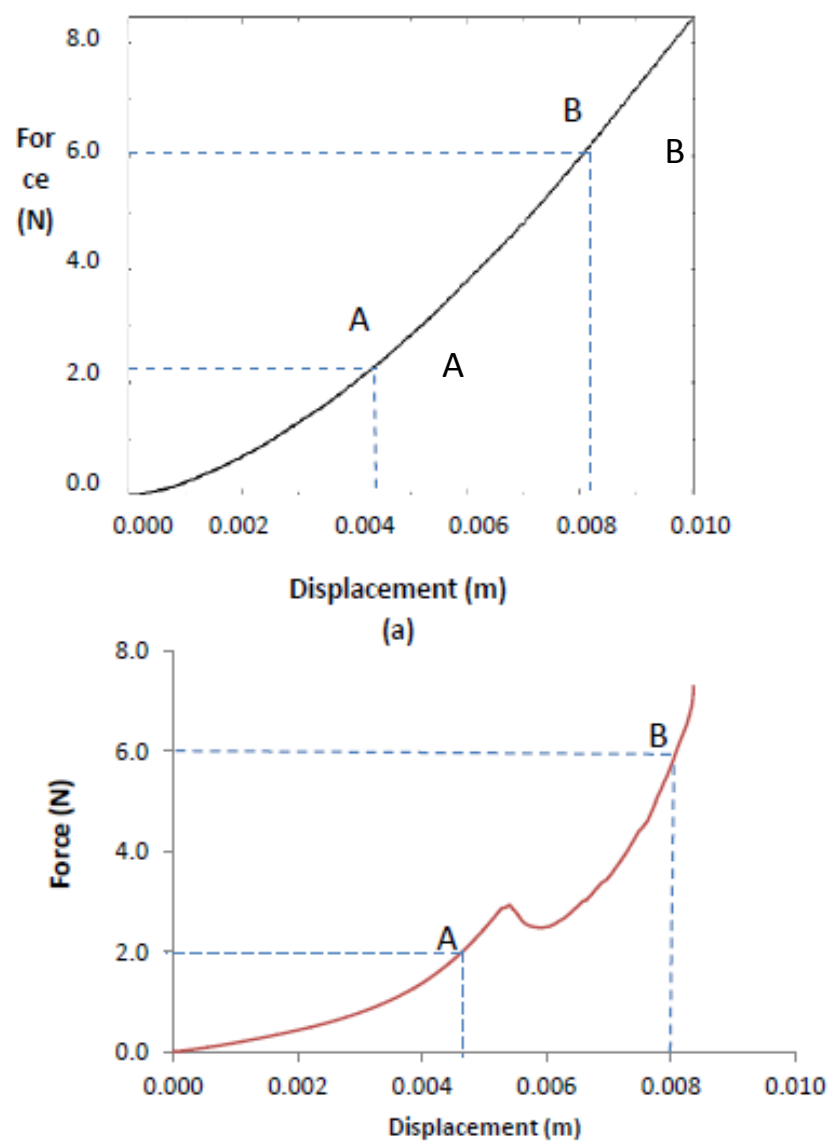

(b)

Fig. 5. (a) The FE analysis and (b) experimental graphs for a sample with $10 \mathrm{~mm}$ diameters.

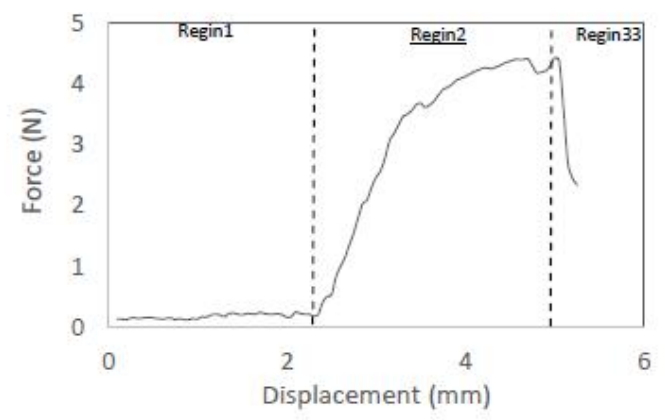

(a)

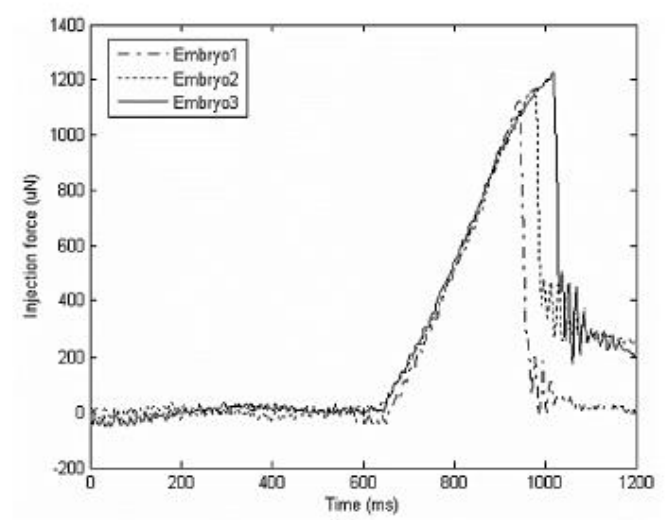

(b)

Fig. 6. The comparison between the injection test on samples and the reported injection force on oocyte [1].

\section{CONCLUSION}

This paper proposes an artificial material in order to develop an artificial oocyte for mechanical properties analysis. The main purpose of the suggested material is to closely mimic the mechanical properties of a human oocyte. The behavioural reaction of the fabricated gel has been tested with satisfactory results in the form of injection forceartificial oocyte deformation relationship. This work is the first reporting of the proposed artificial material to simulate human oocyte. The results demonstrate that the crosslinked alginate gels can mimic the properties of human oocytes and can open new horizons in the use of artificial oocytes in medicine. The benefits include treatment of damages cells, drug deliveries, and laboratory experiments without a need to use real cells.

\section{REFERENCES}

[1] Y. H. Tan, D. Sun, and W. H. Huang, "A mechanical model of biological cells in microinjection," in Proc. International Conference on Robotics and Biomimetics, 2008.

[2] C. A. Amorim and A. Shikanov, "The artificial ovary: Current status and future perspectives," Future Oncology, vol. 12, no. 19, pp. 2323 2332, 2006.

[3] J. Vanacker, M. M. Dolmans, V. Luyckx, J. Donnez, and C. A. Amorim, "First transplantation of isolated murine follicles in alginate," Regenerative Medicine, vol. 9, no. 5, pp.609-619, 2014

[4] J. Sun and H. Tan, "Alginate-based biomaterials for regenerative medicine applications," Materials, vol. 6, no. 4, pp. 1285-1309, 2013.

[5] J. Vanacker, V. Luyckx, M. M. Dolmans, A. D. Rieux, J. Jaeger, A. V. Langendonckt, J. Donnez, and C. A. Amorim, "Transplantation of an alginate-matrigel matrix containing isolated ovarian cells: First step in developing a biodegradable scaffold to transplant isolated preantral follicles and ovarian cells," Biomaterials, vol. 33, no. 26, pp. 60796085, 2012.

[6] E. R. West, M. Xu, T. K. Woodruff, and L. D. Shea, "Physica properties of alginate hydrogels and their effects on in vitro follicle development," Biomaterials, vol. 28, no. 30, pp. 4439-4448, 2007.

[7] P. K. Kreeger, J. W. Deck, T. K. Woodruff, and L. D. Shea, "The in vitro regulation of ovarian follicle development using alginateextracellular matrix gels," Biomaterials, vol. 27, no. 5, pp. 714-723, 2006.

[8] S. J. Bryant, T. T. Chowdhury, D. A. Lee, D. L. Bader, and K. S Anseth, "Crosslinking density influences chondrocyte metabolism in dynamically loaded photocrosslinked poly (ethylene glycol) hydrogels," Annals of Biomedical Engineering, vol. 32, no. 3, pp.407417, 2004.

[9] J. L. Drury and D. J. Mooney, "Hydrogels for tissue engineering: scaffold design variables and applications," Biomaterials, vol. 24, no 24, pp. 4337-4351, 2003.

[10] K. Y. Lee, J. A. Rowley, P. Eiselt, E. M. Moy, K. H. Bouhadir, and D. J. Mooney, "Controlling mechanical and swelling properties of alginate hydrogels independently by cross-linker type and crosslinking density," Macromolecules, vol. 33, no. 11, pp. 4291-4294, 2000.

[11] A. M. Hajiyavand, M. Saadat, and A. Stamboulis, "Abstract, analytical and mechanical modelling of a proposed hydrogel using FE software to simulate the ICSI injection process," Internal Communications, University of Birmingham, Birmingham, UK, 2013.

[12] Y. Sun, K. T. Wan, K. P. Roberts, J. C. Bischof, and B. J. Nelson, "Mechanical property characterization of mouse zona pellucida," Ieee Transactions on Nanobioscience, vol. 2, no. 4, 2003.

[13] W.W. Feng and J. O. Hallquist, "On mooney-rivlin constants for elastomers. stress," Force Per Unit Undeformed Area, 2017.

[14] M. Shahzad, A. Kamran, M. Z. Siddiqui, and M. Farhan, "Mechanical characterization and FE modelling of a hyperelastic material," Materials Research, vol. 18, no. 5, pp. 918-924, 2015.

[15] J. Vanacker, V. Luyckx, M. M. Domans, A. D. Rieux, J. Jaeger, A. V. Langendonckt, J. Donnez, and C. A. Amorim, "Transplantation of an alginate-matrigel matrix containing isolated ovarian cells: first step in developing a biodegradable scaffold to transplant isolated preantral follicles and ovarian cells," Biomaterials, vol. 33, no. 26, pp. 60796085, 2012. 
[16] J. Vanacker, M. M. Dolmans, V. Luyckx, J. Donnez, and C. A Amorim, "First transplantation of isolated murine follicles in alginate," Regenerative Medicine, vol. 9, no. 5, pp. 609-619, 2014

[17] J. L. Drury, R. G. Dennis, and D. J. Mooney, "The tensile properties of alginate hydrogels," pp. 3187-3199, 2003.

[18] A. D. Augst, H. J. Kong, and D. J. Mooney, "Alginate hyrogels as biomaterials. macromolecular," Issued by Harvard University, 2006.

[19] M. Carin, D. B-Biesel, F. E-levy, C. Postel, and D. C. Andrei, "Compression of biocompatible liquid-filled HSA-Alginate capsules: Determination of the membrana mechanical properties," Biotechnology and Bioengineering, vol. 82, pp. 707-212, 2003.

[20] M. M. Stevens, H. F. Qanadilo, R. Langer, and V. P. Shastri, "A rapid-curing alginate gel system: Utility in periosteum-derived cartilage tissue engineering," Sicence Direct, pp. 887-894, 2003.

[21] Hedrih and N. Jelka, "Modeling oscillation of zona pellucida before and after fertilization," Issue Department for Bio-Chemical and Medical Science, State University of Novi Pazar, 2011.

[22] N. A. Peppas, "Hydrogels," ElsInvalid source specified.evier, San Diego CA 2004.

[23] Y. Tan, D. Sun, and W. H. Huang, "Mechanical modeling characterization of biological cells using microrobotics cell injection test bed," in Porc. IEEE/RSJ International Conference on Intelligent Robots and Systems, 2009.

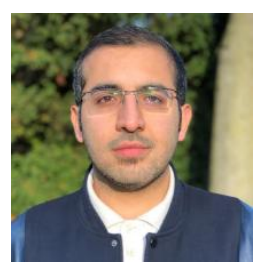

Amir M Hajiyavand obtained his MEng degree in mechanical engineering, biomechanics from the University of Birmingham, Birmingham, UK in 2012. He is currently a doctoral candidate in the field of bio micro robotic in the same university. His main research interests include developing automated systems for micro implant, microinjection, and micromanipulation of biological systems.

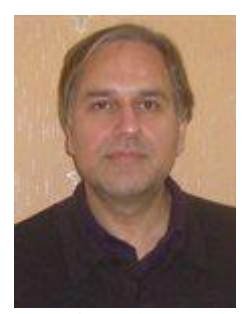

Mozafar Saadat holds an honours degree in mechanical engineering from University of Surrey, and $\mathrm{a} \mathrm{PhD}$ in manufacturing automation from University of Durham, both in the UK. He has had a range of previous experience as manufacturing technology consultant to industry. He has obtained research funding in electronics, manufacturing and aerospace sectors and has published widely in leading international journals. His research interests are in the areas of automation, robotic, manufacturing engineering, and intelligent systems.

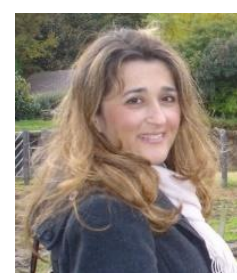

Artemis Stamboulis obtained a BSc in chemistry (biochemistry) from the Kapodistrian University of Athens, an MSc in polymer science and technology from UMIST and a $\mathrm{PhD}$ in polymer science and engineering from the National Technical University of Athens in 1997. Artemis' main research interests are in the microstructural characterisation of materials for biomedical applications as well as in multifunctional materials with emphasis in orthopaedic antimicrobial materials. She has published over 70 research papers in international scientific journals. 